\title{
Hijacking the Narrative: \\ The First World Forum on Natural Capital, \#natcap13, and Radical Dissent
}

Brett S. Matulis

Jessica R. Moyer

ABSTRACT: The first World Forum on Natural Capital was an important moment in the production of "valued" nature. It brought together bankers, CEOs, and business elites to promote financialized environmental accounting as a solution to ecosystem degradation. Anti-capitalist activists, however, opposed the further intrusion of economic logic to environmental decisionmaking and resisted its progression. While WFNC organizers were able to advance the concept of "natural capital" through traditional (print and web 1.0) media, they struggled to control the social media narrative. Digital activists were able to challenge the official narrative on Twitter and compel organizers to address the associated social and environmental justice concerns. As such, social media produced the conditions for both abstracting nature into value-bearing commodities and, simultaneously, resisting such abstraction. Drawing on theories of counterpublic organization, public spheres of deliberation, and agonistic confrontation, this paper explores the discursive coproduction of nature in a new digitally-mediated world.

KEYWORDS: natural capital; counterpublic; deliberative democracy; activism; twitter

\section{Section I: Introduction}

According to the website of the first World Forum on Natural Capital, a "revolution is taking place"

(World Forum 2013a). But this is not a grassroots revolution of the people. It is a revolution "in how businesses and governments account for natural capital" (ibid.). At many levels of society, ecosystem functions and natural resources are being recast as "services" and "capital", in order to conform to the dominant language of business and government. The objective is arguably little different from those that have existed for decades - to manage limited resources and protect important environments - but, as described elsewhere (Carver and Sullivan 2014; Sullivan 2014), this move is significant in that it seeks to reconcile the inherent tension between conservation and development by bringing conservation into alignment with the logics of capitalist economics.

The World Forum on Natural Capital (which we will refer to variously as WFNC, \#natcap13, or simply "the Forum"), was organized by the Scottish Wildlife Trust after establishment of the Natural Capital Declaration at Rio+20 in 2012. The Declaration was a commitment by "the financial sector to work towards integrating natural capital criteria into financial products and 
services" (Declaration 2012), and the WFNC was the first public event where the sector came together to act on their commitment. The objective was to advance the concept of natural capital and promote methods of accounting to the uninitiated. Attendance to the Forum was targeted at “[f]orward-looking” CEOs, CFOs, management level business operatives, economists, and "other influencers" from around the world (World Forum 2013b). A $£ 795$ registration fee for the two-day event ensured that only the higher echelons of society would have access. ${ }^{1}$

Exclusive as it was, the event further promoted an inner circle, invitation-only "CEOs' Club", 2 which offered "the most senior delegates ... an opportunity to contribute to one of the key outcomes from the event" (World Forum 2013c; also noted in Sullivan 2014). Delegates to the Forum included representatives from the Royal Bank of Scotland (which invests heavily in oil and gas), Rio Tinto (a mining company with a long record of environmental and human rights abuses), BP, Shell, Weyerhaeuser (a timber products producer and one of the world's largest private owners of forest land), and Nestlé (whose chairman has spoken candidly about the advantages he perceives in the privatization of water, casting the view of a public right to water as "extreme"). ${ }^{3}$ The highest ranks of government also spoke in support of WFNC activities, including a keynote address by First Minister Alex Salmond and a recorded message of support from Deputy Prime Minister Nick Clegg.

Simultaneously, as the business and government elite explored new opportunities presented in the application of economic logic to environmental conservation, the event also served to normalize the idea in popular imaginations that financialized approaches are an appropriate means of protecting important biological systems. A multifaceted media strategy utilized print, broadcast, and digital media (including newspaper editorials, BBC Radio Scotland, the Guardian Sustainable Business blog, and, importantly, web-based social media) to cast the ideology of capitalist conservation as commonsense. 
In response, anti-capitalist (or at the very least, skeptical) activists mounted a campaign to counter this narrative and resist the growing encroachment of liberal economic concepts. While the WFNC was largely able to advance a particular narrative within the actual event and in traditional (i.e. print and web 1.0) media, Forum organizers struggled to control the outward message on Twitter, one of the more active and prominent publicity channels for the event. At the margins, digital activists were able to challenge the official narrative and even force Forum organizers to address the associated social and environmental justice concerns.

This paper is an analysis of political conflict in the "virtual public sphere", the mobilization of an anti-capitalist counterpublic, and the radical potential in digitally-mediated resistance. In the pages that follow, we develop a theoretical framing that draws upon (and critically engages with) "liberation technology", deliberative democracy, notions of the "public sphere", and agonistic pluralism. Situating these concepts in the context of Twitter-based resistance to the WFNC, we explore the radical opportunities (as well as neoliberal hazards) that exist in contemporary digital society. The paper is organized as follows: section II provides a conceptual framework for understanding online activism; section III concerns the methodological considerations of participant-based online research; section IV explores the case of \#natcap13; and section V concludes by re-engaging with theory to push forward our understanding of counterpolitics in a digitally-mediated world.

\section{Section II: Understanding Digital Activism}

\section{Liberation Technology or the Neoliberalization of Dissent?}

Popular awareness of the role social media can play in facilitating, coordinating, and galvanizing political action developed in light of civil unrest ranging from the Arab Spring to Occupy Wall Street, Ukraine's Euromaidan, and \#BlackLivesMatter. The power of new information and 
communication technology (ICT) to spur popular movements and uprisings is now commonly accepted. Noting the "striking ability of the Internet ... to empower individuals, facilitate independent communication and mobilization, and strengthen an emergent civil society", Larry Diamond conceives of "liberation technology", which he takes to be "any form of information and communication technology that can expand political, social, and economic freedom" (Diamond 2010:70). As he indicates, there is enormous potential in ICT to "empower those who wish to ... challenge authoritarian rule" (Diamond 2010:71).

At the same time, however, Diamond cautions against thinking of "the Internet as unprecedented in its potential for political progress" (2010:71). Indeed, many revolutionary technologies have come before it (e.g. the printing press and telegraph; Diamond 2010), and authoritarian regimes have taken extraordinary measures to censor digital media, subdue digital activism, and suppress dissent (Morozov 2011). Warf and Grimes (1997) similarly identify the potential of the internet to foster counterhegemonic activity, but caution that it equally empowers the far-right, asserting that it is "neither inherently oppressive nor automatically emancipatory" (1997, 259). An alternative framing can even cast new digital technology as regressive, in terms of enabling expanded capabilities in state and corporate surveillance (looking no further than the US National Security Agency's bulk collection and data monitoring programs or Google's AdSense). In recognition of this, Diamond explains that "[i]n the end, technology is merely a tool, open to both noble and nefarious purposes" (2010:71), and he is circumspect in describing the potentials and pitfalls in "liberation technology".

Nevertheless Diamond's (2010) intervention leaves the critical reader wanting; he does not adequately conceptualize the role of new digital technology in democratic governance or theorize its broader place within the entrenched political economy and existing hegemonic order. Beyond simply providing an account of the progressive possibilities (and regressive hazards) inherent to 
information and communication technology, we need, as Roberts suggests, "to ask how new media becomes embedded into current social practices" and, in turn, to understand "how this creates new [ones]" (2014:12). In order to fully appreciate the emancipatory potential of ICT - and to recognize how it is simultaneously deployed in service of wealth and power - we must first understand its articulation within the theoretical terrain of deliberative democracy, neoliberal governance, and political struggle.

The Habermasian conception of deliberative democracy underpins much of the literature optimistic about technologically mediated governance. In this frame, the internet and social media are understood to facilitate progress towards Habermas's "ideal speech situation" where "public dialogue is free and uncoerced" (Kapoor 2002:462). Under these conditions, consensual decisions may be reached "by the (unforced) 'force of the better argument"' (Kapoor 2002:462). Roberts (2014), however, is not convinced that deliberative conditions empower the politically marginal, and he interprets deliberative democracy as an element of neoliberal governance wherein the state enters in "partnerships" with private and (often) corporate entities. From his perspective, the deliberative principles that open governance to a broader range of actors simply mask the inequities between the various "partners" and enable the leverage of private interests. As Hirsch observes, deliberative concepts may "reduce democracy to processes of negotiation ... between extremely unequal actors" (2003:244).

Roberts (2014) further critiques deliberative democracy in the context of new digital technologies, noting the various ways they have undermined deliberative ideals. In particular, he identifies the way that "the capitalist public sphere is regularly employed as a communication tool for the rich and powerful" (Roberts 2014:20). As we explain below, this is precisely what the WFNC attempted in its \#natcap13 media strategy, which sought to mobilize digital communication technology in service of entrenched capitalist interests. On the other hand, we also show that the activist response 
pushed back against these moves, challenging the \#natcap13 deliberative space and calling into question the purported "debate" that was taking place within the (prohibitively expensive) physical spaces of the event itself. The online activists, in effect, hijacked the narrative - or 'piggy-backed' the official PR campaign (Adams 1996) - with the aim of disrupting the capitalist worldview embedded within it. While this action, as we discuss below, might be characterized as a form of “trolling”, it was trolling with a purpose.

Despite such openings for contestation, however, Roberts (2014) remains skeptical of the power of "new media" based social movements to open the field to radical politics - that is, to recognize social problems, not as isolated ills, but as symptoms of a diseased political system requiring holistic treatment and structural transformation. Roberts suggests that new media based social movements are too deeply embedded in political liberalism and too closely associated with the ideologies that sustain neoliberal capitalism to drive systemic change. From his perspective, social media "produces a type of networked activism that inadvertently supports and bolsters an individualist neoliberal culture that can ... frustrate building grassroots activism within civil society" (2014:91). ${ }^{4}$ Roberts fears that social media serves to produce neoliberal subjectivities, and he thus questions the extent to which digital social movements pose a challenge to neoliberal hegemony.

While acknowledging that "[d]igital technology both empowers capitalist ideology and destabilises it to some degree", Roberts argues that it also "regularly reproduces existing social divisions and social hierarchies" (2014:94). Purcell further notes the way in which the internet can produce "echo chambers and information cocoons that undercut ... a robust public sphere" (2014:139). Far from opening the field to radical politics, new technology can reinforce the hegemonic order by reproducing existing power relations in the virtual public sphere. The way to avoid this pitfall is by examining new digital communication technologies within their capitalist contexts, thereby 
avoiding an overly optimistic understanding of the democratic potential in new media (Roberts 2014). Rather than accept the taken-for-granted notion of social media as a virtual "public sphere" for democratic deliberation, it is perhaps better to understand the way that it may serve to foster important "counterpublics" for agonistic confrontation. In the case of \#natcap13, in fact, it was not that Twitter served as a means to facilitate deliberative engagement, but that it opened space for oppositional democratic politics.

While Habermas conceived of an idealized space in which deliberative decision making could take place, others including Nancy Fraser have questioned the extent to which this is the case. As Fraser (1990) contends that "the ideal of participatory parity ... [may be] more closely approximated by arrangements that permit contestation among a plurality of competing publics than by a single, comprehensive public sphere" (1990:68). Similarly, Mouffe (1999) conceptualizes "agonistic pluralism" as a means to open space for democratic contestation. Critical of the rationalism inherent to deliberation, and seeing that it "erases the dimension of the political" (1999:745), Mouffe explains that "what is really at stake in the critique of 'deliberative democracy' ... is the need to acknowledge the dimension of power" (1999:752). Power is bracketed from politics when deliberation places stakeholders on ostensibly equal footing, effectively lending consultative legitimacy to the advancement of dominant perspectives at the same time that it neutralizes dissent. Against this consensus-based conception of democracy, agonism embraces conflict as an essential element of democratic politics.

\section{Digital Agonism}

With the advent of "web 2.0" technologies (Barassi and Treré 2012), important new opportunities for agonistic politics and counterpublic organization are formed (Cammaerts 2008). The interface of this new digital political terrain with environmental conservation is captured in the concept of "nature 2.0" (Büscher 2013), and though the prosumptive dynamics of digitally-mediated nature 
conservation may intensify capitalist attempts to generate new modes of accumulation (Büscher and Igoe 2013:283), these dynamics also provide openings for resistance and anti-capitalist organization. New digital technologies have the potential to facilitate agonistic confrontation and empower marginalized counterpublics to engage in such ways.

As Penney and Dadas identify, Twitter and other technologies that circulate digital media allow "protestors to very quickly build a geographically dispersed, networked counterpublic that can articulate a critique of power outside of the parameters of mainstream media" (2014:88). Indeed, they suggest that these new means of communication "are not only amenable to the intensive textual circulation necessary for building and sustaining a counterpublic", they may actually foster their development (Penney and Dadas 2014:89). In other words, new technological regimes may facilitate both enhanced and expanded counterpublic activity. In one case, for example, academic email listservs (a somewhat older form of social media) were used to mobilize a global network of academics to successfully press for the release of an imprisoned geographer (de Socio 2010).

Largely optimistic about the unprecedented organizational capacity of digital networking, Penney and Dadas do acknowledge structural vulnerabilities, since networks are "administered by external commercial entities" and, therefore, not entirely under the control of counterpublic movements (2014:89). Going beyond simply the concern that counterpublics may not have full control over the means of communication, Papacharissi (2002) suggests that new technologies may lack the capacity to fundamentally alter the existing social order; "given the patterns of global capitalism, it is possible that internet-based technologies will adapt themselves to the current political culture, rather than create a new one" (2002:9). She remains unconvinced that the internet is facilitating enhanced democracy or fundamentally altering the status quo. Büscher, as well, observes that social media allow corporate, government, and third sector actors to "influence, modify, and even 'co-create"” representations of nature to suit their ideologies and political struggles (Büscher 2013:1). 
Papacharissi (2002) suggests that new digital technologies may extend the realm of political discussion, but do little to change the culture of politics or the structural inadequacies of the political system. The "virtual sphere", in Papacharissi's view, simply reproduces existing politics, "serving as a space for additional expression, rather than radically reforming political thought and structure" (2002:14).

Davis (2010) provides evidence that much of existing politics is carried over into the virtual realm, pointing to the closed circles of elite communication within digital political networks. In other words, political elites remain rather insular in their use of social media, choosing to use platforms such as Twitter for additional one-to-many communication and declining to engage in the 'two way' communication that web 2.0 media are supposed to facilitate. As such, Davis suggests that new digital technologies are "unlikely to [offer] a solution to wider patterns of public disengagement from institutional politics" (2010:746) and, thus, these new tools may be better suited "to organize opposition to politicians and political institutions" (ibid., 747).

Despite it being unclear the extent to which the public has gained political advantage - since digital technologies "also enhance the communicative abilities of those same political and corporate actors, at the centres of decision-making" (Davis 2010:748) - there is reason to believe it enables significant political change. Dahlberg (2007), for example, suggests that the internet may actually work to radicalize the public sphere. Drawing on an agonistic conception of the counterpublic sphere, Dahlberg develops a conception of the virtual sphere that "account[s] for the democratic role of radical exclusion and corresponding inter-discursive contestation" (2007:48). There are three parts to his argument that the internet can be "seen as a force for 'radical democracy"' (Dahlberg 2007:56). First, the internet provides space for marginalized discourses to develop counterpublics. Second, it enables diverse and dispersed counterpublics to find "shared points of identity" and "gives strength to marginalized publics weakened by isolation" (Dahlberg 2007:56). 
And, third, it "supports online and offline counter-public contestation of dominant discourses" (Dahlberg 2007:56). It is these points of departure that we will use to explore the radical counterpolitics of discursive contestation surrounding the WFNC. This case aims to show how technology may be used to radicalize the public sphere and intervene in the "civil" deliberations of the political and corporate elite.

\section{Section III: Total Participation and "Discovering" Data}

Methodologically, this paper retrospectively applies an analytical framework to encounters in which one of the authors (Brett) was previously engaged as a participant rather than a researcher. At the time of the WFNC, his research focused primarily on critiques of ecosystem services and natural capital. A familiarity with the hazards of a financialized approach to conservation meant that he was also a political opponent of the concepts and the application of capitalist logic to nature conservation, more generally. This was largely because of a sense that the same ideologies responsible for the recent global financial crisis could not hold the solution to our mounting environmental crises. Indeed they would likely deepen the problem and generate even greater social inequity. This perspective was shaped by the critical academic literature on the neoliberalization of nature and capitalist nature conservation (e.g. Arsel and Büscher 2012; Brockington and Duffy 2010; Büscher et al. 2012; Castree 2008a; Castree 2008b; Robertson 2012; Sullivan 2013). As such, Brett was engaged on the sidelines of the WFNC as a critical observer and participant in activist resistance.

Now, in an effort to better understand digital dissent, we are reflecting on Brett's experiences and retrospectively conceptualizing the encounters. To do so, we utilize a range of methods and data sources. The primary body of data on which this paper is based is that generated from Twitter activity around the event. With one of us having previously played an active role in generating these data, we now employ reflexive and analytical tools from autoethnography (Ellis et al. 2011; 
Ellis and Bochner 2000) as well as critical discourse analysis (Wodak and Meyer 2009) to gain new insight on what occurred. This includes consideration of Brett's own contributions as "discovered" in the dataset. Importantly, the distinction we are drawing here (between "total participant" and "researcher") is not intended to suggest that we can, in any way, step outside of our positioned roles as political beings and/or activists. Rather, we set out to retroductively describe our analytical process (Kendall 2007), the first stage of which involves re-examination of Brett's tweets as if they are merely "found data".

To supplement this primary data source, the second stage of the analysis involves a deeper probing into what Weber (1947) referred to as "verstehen", or in other words the meaning and intentions behind the described Twitter activity, as attributed by central actors themselves. Alongside examination of encounters from Brett's recollection, we consider archival video footage from the counter-Forum livestream, as well as additional personal accounts obtained through interviews with key informants, who were selected for the roles they played in coordinating the WFNC and counterForum, respectively. Significantly, our analysis does not include any firsthand data from inside the WFNC, for the simple reason that we were unable, as ordinary members of the public, to afford (even the discounted "non-corporate") registration fee, an important factor that framed public perception and spurred counterpublic organization.

In considering the primary data, we apply a form of retrospective participant observation. As Fisher and Anushko explain, this method "uses retrospective observations from previous experience when [the researcher] was a total participant prior to any research interest" (2008:102). As such, it offers unique insights and cultural knowledge from a first-hand perspective. At the same time, as with any method, it has limitations worthy of careful consideration. Collinson (2009:20), for example, points to "subjective partiality" and even "nostalgia" as potentially complicating factors. To manage these, we follow Bayard de Volo and Hall (2015) and 'triangulate' Brett's observations with both key 
informant interviews and the digital record of the tweets themselves. This strategy additionally increases the reliability of "retrospective recall" (Bozionelos 2014). The risk of participant bias is further minimized by the presence of a co-author (Jessica) who did not participate in the Twitter discussion surrounding the WFNC, and can therefore provide an 'outsider' perspective to be collaboratively reconciled with that of Brett's 'insider' view (see Bayard de Volo and Hall 2015 for further description of the advantages of insider-outsider co-authorship and its associated 'checks and balances' system).

Bulmer (1982), who originally conceived of retrospective participant observation as a technique, did so in a climate of increasing regulation of research and in response to ethical concerns that covert observation violates the principle of informed consent. It is true that certain ethical considerations arise in a case such as this where participants were not aware that their Twitter activity would later be subjected to critical analysis, and therefore could not give consent to participate in the research. As Bulmer describes, however, in applying observation analysis retrospectively, “[n]o deception of those studied [is] involved [and] no breach of informed consent occur[s], since no scientific study was in view at the time the study was carried out" (1982:255). While it can be debated whether this technique resolves ethical concerns to the extent that Bulmer suggests, it does signify that deception, at least, was not part of the data collection methods.

It is also the case that the data we are drawing upon (i.e. the Twitter data and the counter-Forum livestream) are public. We are not exposing personal correspondence without informed consent, but rather applying an analysis to data that is in the public record and available for any researcher (previously involved or otherwise) to evaluate. By the nature of the Twitter platform, users were already aware at the time of production that their data were public, and all participants at the counter-Forum were made aware of the livestream recording at the start of the event. 
Additionally, unlike the extensive user information that can be accessed on other social media platforms that have more complex privacy options and multiple privacy spaces (e.g. Facebook, as discussed by Zimmer 2010), the Twitter data collected for this study reflect universally available, manually retrieved (as opposed to machine-read), and subject-relevant user comments rather than personal profile data. It is still possible that participants may have engaged in different ways and on different terms had they known that their contributions would later become the subject of research. However this point, while worthy of ethical consideration, also represents a strength of the present research in that the data collected are 'naturally occurring' and therefore unaltered by selfcensorship.

Our analysis of the Twitter data included a comprehensive review of the tweets on the official \#natcap13 hashtag from the start of its use on 9 May 2013 through 21 November 2014, a full year after the event and well after the hashtag had fallen into disuse. This was done in the only way possible, manually using Twitter's standard interface and search filters, since corporate policies treat the data as proprietary and restrict historical access to it in any other way. In fact, because of these restrictions, we found that a single Twitter search would not return the full content that we knew to exist and had, in fact, omitted at least one of Brett's own tweets. To circumvent this constraint, we performed the \#natcap13 search multiple times with narrowed date ranges until the searches produced no new results. We then used consecutive date-constrained searches to ensure that the complete results for \#natcap13 had been retrieved. This was practical only because the \#natcap13 dataset was in the order of thousands, not millions of tweets.

Secondly, we reviewed the individual Twitter feeds of key users, whose contributions had featured prominently in the social media discourse on WFNC. We identified these key users through either their numerous appearances in the search results described above, or the fact that their tweets solicited direct responses from other users and therefore propelled further discussion. This second 
pass through the data resembled the "snowball method" of sampling, in that we used associations and interactions between individual users to traverse the data non-sequentially. While its results were largely redundant of the initial search, this process allowed us to consider a few further tweets about the WFNC that continued horizontally in conversation threads from \#natcap13 but were not tagged themselves (due to space constraints, oversight, typos, etc).

As a final cross-check aimed at ensuring that no tweets had been overlooked, we repeated the initial search method for the alternative \#notforsale hashtag that was occasionally used by members of the counterpublic, beginning 12 November 2013 when it came into use. This search produced no additional results beyond those retrieved in the previous two steps. As explained in the next section, the significant overlap in search results above, and the fact that so much of the Twitter discourse was captured by the \#natcap13 hashtag, speaks to the very nature of the digital activism exercised by the counterpublic in this case. Specifically, the resistance that was generated in opposition to WFNC mobilized around a mission to not simply reject the Forum's agenda, but to appropriate its existing digital infrastructure and hijack its message.

\section{Section IV: Hijacking the Narrative}

\section{Challenging the Dominant Message}

The WFNC was announced in May 2013, and the official @ NatCapForum account began promoting the event soon thereafter. Initially, content was largely informational. The announcement was well received and celebrated by those within business and business-oriented conservation networks. The account quickly gained followers with the assistance of influential and highly networked supporters, partners, and affiliates such as the IUCN, WBCSD, and The Wildlife Trusts. The position of \#natcap13 was presented as progressive and business-friendly, though otherwise avoided explicit political engagement.

World Forum on Natural Capital, Edinburgh $21 \& 22$ Nov. Website now live: http://www.naturalcapitalforum.com/ \#natcap13 (@NatCapForum 10:43 AM, 15 May 
$2013) .^{5}$

Find out why \#NatCap13 is necessary and why You should be there:

http://www.naturalcapitalforum.com/the-need-for-this-event \#CSR \#Sustainability (@NatCapForum 6:12 PM, 16 May 2013). ${ }^{6}$

Why are companies interested in Biodiversity? Joshua Bishop from @WWF \& @ TEEB explains: http://t.co/ZsvEINLkEt \#CSR \#NaturalCapital (@ NatCapForum 10:21 AM, 20 May 2013). ${ }^{7}$

Our partners @IUCN Business and Biodiversity Programme explains the \#Business case for enhancing \#Biodiversity

http://www.iucn.org/about/work/programmes/business/bbp_aboutus/bbp_case/

(@NatCapForum 11:36 AM, 21 May 2013). ${ }^{8}$

In the early months, there was virtually zero dissent. One of the very first to express concern over the natural capital agenda and catch the attention of Forum organizers was a user called "Ginny" (@ginbat). She was dismayed over the "energy/resources/time" being devoted to progressing the initiative without any "real public debate". 9 Allan Bantick (@ AllanBoat), then chairman of the Scottish Wildlife Trust, and the official @ NatCapForum engaged to assure Ginny that the WFNC was being organized to initiate that debate, though it was made clear they were working "with the aim of moving debate into action". ${ }^{10}$ Ginny protested that, if there was any debate, it could hardly be considered "public". ${ }^{11}$ Rather prescient of what the WFNC would prove to be - that is, a business meeting largely insulated from popular concerns - Ginny noted that policies were already forming in, and emanating from, elite circles without broad democratic buy-in. ${ }^{12}$

I, myself, ${ }^{13}$ tweeting from @ bmatulis, challenged the WFNC on this issue of "debate" and exclusivity. The entrance fee on the event, I protested, ensured "that only the highest elites will have access", meaning that the "halls of power are closed". ${ }^{14}$ When I charged that the WFNC was “for CEOs and CFOs", not "those concerned about social justice and equity", Programme Director Jonathan Hughes (@JonnyEcology) assured me that the event was “competitively priced” for such a global meeting. ${ }^{15}$ Following this response, which exhibited precisely the capitalist elitism my tweet had criticized, I began in July 2013 to periodically inject tweets on their \#natcap13 hashtag countering the initiatives and narratives they were advancing. I felt compelled to not allow the 
event, happening in my own city, to go unchallenged. Even if exorbitant fees could prevent me from raising these issues from within, nothing could stop me from disrupting the narrative the forum organizers wanted to promote on social media.

Conservation is too important to be an investment opportunity. Must focus on \#environmentaljustice, not \#natcap13 http://www.naturalcapitalforum.com/ (@ bmatulis 4:10 PM, 3 Jul 2013). ${ }^{16}$

"The Natural Capital Myth is colonising our imaginations" @SianSullivanUK http://ppel.arizona.edu/blog/2013/03/15/natural-capital-myth \#natcap13 (@ bmatulis 9:08 AM, 6 Jul 2013). ${ }^{17}$

Royal Bank of Scotland is "headline sponsor" for \#natcap13. "Beware of listening to this imposter" http://140charactersarenotenough.tumblr.com/post/56415870977/discourse-oninequality (@bmatulis 10:01 AM,4 Aug 2013).18

RBS is adding ecosystems to their portfolio! Alongside cluster bomb manufacturers, tar sands extraction, \& Belarussian dictators \#natcap13 (@bmatulis 3:01 PM, 5 Aug 2013). ${ }^{19}$

Seductively logical, but \#naturalcapital extends the reach of capitalism, will lead to dispossession http://www.theguardian.com/sustainable-business/graphic/what-is-naturalcapital-infographic \#natcap13 (@bmatulis 1:07 AM, 25 Oct 2013). ${ }^{20}$

Make no mistake, \#natcap13 is about surrendering conservation decisions to bankers and CEOs (@bmatulis 4:53 PM, 4 Nov 2013). ${ }^{21}$

Few people acknowledged these efforts, and fewer joined in support. My protests were easily ignored by those already convinced of the merits to natural capital accounting. Though WFNC organizers regularly engaged with users on social media, they chose not to entertain my polemical interventions. Nevertheless, social media proved a useful tool for exposing the controversial nature of the Forum agenda, despite its apolitical pretense. Twitter in particular served an effective intermediary role, as demonstrated in the excerpts above, by encouraging public audiences to view a range of relevant promotional, online, and traditional media sources through a critical lens. What could arguably be considered "trolling" was actually being conducted with constructive political aims in mind, which is consistent with certain assessments of the practice (Bartlett 2014) as the wider trolling phenomenon routinely drifts between malicious triviality and purposeful engagement in global political issues (Coleman 2014). The tactic of narrative disruption enabled a kind of quiet mobilization, of skepticism if not outright opposition, that became increasingly hard for Forum 
organizers to ignore.

At one point in late October, after launching the WFNC infographic, the @ NatCapForum account solicited comments from users, including some known skeptics such as Chris Lang (@ reddmonitor): "New \#NatCap13 infographic ... Interested to get your thoughts". ${ }^{22}$ Lang responded:

In 140 characters? OK I'll give it a go: Bollocks. Scary. Your sponsors include RBS http://bit.ly/1do2n8d Need I continue? @ NatCapForum (@ reddmonitor 7:16 PM, 24 Oct 2013). ${ }^{23}$

The link he included points to a Platform report exposing RBS as Europe's chief financier of new oil and gas exploration. His implication was that this activity by the event's headline sponsor discredited any claim to serious environmental concern. The WFNC responded that they were “aiming for a lively debate, [and Lang's] views would be very welcome". ${ }^{24}$ Lang declined the invitation to participate, pointing to the unreasonably high registration fee and suggesting their "debate" amounted to little more than a greenwash. ${ }^{25}$

This exchange is particularly revealing of how the opposition perceived the WFNC. Invitations to join their debate were understood as empty gestures designed to establish the impression of inclusivity without offering serious consideration of dissenting views or any real opportunity to alter the direction of policy. As @EcoLabs put it "I understand that the @NatCapForum would like to appear to be open for debate - but this is not actually the case". ${ }^{26}$ The perception among dissenters was that Forum organizers sought merely to acquire consultative legitimacy for a preestablished agenda - indeed the event program had already been set. ${ }^{27}$ If the Forum could be portrayed in the traditional media as broadly inclusive of a diverse community that had come together and exchanged ideas, its outcome would seem to reflect rational "public opinion" and need not acknowledge the bracketing of power relations or unequal footing of the different parties involved. 


\section{An Emergent Counterpublic}

In late October, the opposition became significantly more organized. A network of 18 activist organizations - led by the World Development Movement, Counter Balance, Re:Common, and Carbon Trade Watch - announced the World Forum on Natural Commons (http://www.naturenotforsale.org/), which would be held simultaneously alongside the WFNC in Edinburgh. This counter-Forum was to provide an outlet for those voices that opposed the financialization of nature occurring within the WFNC. Weeks passed before traditional media outlets picked up the event, but in the second week of November, just 8 days before the WFNC was set to take place, The Guardian ran a short article under the title "Wildlife conference under attack for 'selling off nature to multinationals"' (Edwards 2013). While the article made no mention of "\#natcap13", the alternative "\#notforsale", or social media at all, it provided exposure to the growing controversy around the WFNC. As a result, opposition grew rapidly and social media engagement increased accordingly.

This critical moment in the opposition's development highlights the important role that traditional media still play in the advancement of new media campaigns. In the case of the WFNC, however, this role was complementary rather than essential. In contrast to campaigns like "Stop FEMA Now" (Checker 2017) and \#sealfie (Hawkins and Silver 2017), whose successes depended heavily on traditional media exposure and activist organization, the \#natcap13 opposition was able to mobilize prior to and independent of receiving such coverage. The reason for this speaks to the unique tactics the latter group employed.

Whereas the \#sealfie campaign created a new hashtag, for example, WFNC protestors simply hijacked their opponents'. The difference was that \#sealfie activists had to rely upon traditional media coverage to initiate their campaign, while \#natcap13 protestors were able to capitalize on the 
promotional activities of the Forum's PR team. In effect, the \#sealfie activists exploited the active media coverage of Ellen DeGeneres' "selfie seen around the world"28 and subsequent donation to the Humane Society to promote their social media campaign (Hawkins and Silver 2017). This exposure was absolutely critical to the success of the \#sealfie campaign as, without it, only their existing followers (or those that stumbled upon the hashtag) would have seen their tweets. By contrast, any social media user with an interest in the WFNC would have been directed to \#natcap13 by the Forum organizers themselves. Lacking the ability to filter out unwanted perspectives, any social media users who tuned in to the WFNC on the official \#natcap13 hashtag were immediately confronted with outspoken opposition.

While neither the Guardian article nor the counter-Forum played an integral role in the hijacking of \#natcap13, both certainly contributed to the atmosphere of skepticism around the WFNC by amplifying the controversy. The expanded coverage also encouraged a greater number (and diversity) of people to join the fight:

Global finance requires the constant development of new assets: their next target, nature itself. \#notforsale http://www.naturenotforsale.org (@Econopoly 4:34 PM, 15 Nov 2013). ${ }^{29}$

Once a price is put on nature, all of our common resources can be bought, sold and packaged. \#notforsale http://naturenotforsale.org (@EcoLabs 4:48 PM, 15 Nov 2013). ${ }^{30}$

Forum on natural commons \& alternatives to marketisation of nature - in Edinburgh 21st November http://naturenotforsale.org/speakers/ (@EthicsEdinburgh 1:09 AM, 16 Nov 2013). ${ }^{31}$

@ValuingN@reluuplands @economicvoice alternatives to putting a price on nature http://naturenotforsale.org/forum/ \#notforsale \#NatCap13 (@lastbid 6:32 PM, 17 Nov 2013). ${ }^{32}$

This week tell those trying to turn the environment into a financial market that Earth is \#notforsale http://naturenotforsale.org/ (@ nickdearden75 3:19 PM, 18 Nov 2013). ${ }^{33}$

Alternatives to \#naturalcapital? See what is going on at the Forum on Natural Commons http://naturenotforsale.org/forum/ \#natcap13 (@bmatulis 4:50 PM, 19 Nov 2013). ${ }^{34}$

14 organisations from across Europe converging for the Forum on Natural Commons http://naturenotforsale.org/2013/11/20/the-great-nature-sale-has-begun/ \#notforsale (@ ricj1 12:45 PM, 20 Nov 2013). ${ }^{35}$ 
The Great Nature Sale Has Begun http://wp.me/p42i3d-3H \#notforsale (@Paco_Cervera 4:53 PM, 20 Nov 2013). ${ }^{36}$

[W]ell done Scotland fighting to keep nature out of the grasp of global capital http://naturenotforsale.org/ (@ohbaines 7:51 AM, 21 Nov 2013). ${ }^{37}$

With the combined support of a diverse range of individuals and organizations, a clear counterpublic began to emerge. In a pluralistic model more closely resembling "networked individualism" than "collective identity" (Pickerill 2006:274), and especially echoing the theme of “one no, many yeses" (Kingsworth 2003), this counterpublic was united by a shared concern while remaining varied in its affiliations, agendas, and interests. A loose cohesion developed around an anti-capitalist theme which warned against the growing influence and hazards of corporatization, financialization, and marketization. Members of the counterpublic differed in terms of how they described the specific injustices perpetrated by such trends, and on which victims they focused their concern. Their overarching criticism, however, was that the conceptual and practical treatment of nature as a form of capital serves the exclusive agenda of global wealthy elites, at the expense of the rest of us and nature itself.

Those excluded from the deliberative "public sphere" of the WFNC took to the virtual spaces of Twitter to challenge the dominant narrative being advanced. Emboldened by the building momentum, members of the counterpublic became more outspoken, and many began to intervene on the \#natcap13 hashtag, directing their views not just toward a community of like-minded individuals, but also toward those actively advancing the natural capital concept and common users inclined to the seductive new idea.

Don't be fooled. It's all about the money. It will always be about the money \& it'll be at the expense of you, me \& biodiversity \#natcap13 (@SaveOurWoods 2:36 PM, 21 Nov 2013). ${ }^{38}$

Nature is \#notforsale. @ NatCapForum stop pushing corporate control of nature \#natcap13 (@BillLinton 4:49 PM, 21 Nov 2013). ${ }^{39}$

\#natcap13 turning nature into capital will result in increased exploitation of natural resources instead of protecting them \#notforsale (@TonyDickinson2 4:59 PM, 21 Nov 2013). ${ }^{40}$ 
At one point the "top tweet" (as determined by Twitter's internal algorithms) ${ }^{41}$ was from the World Development Movement (@wdmuk) challenging the mainstream notion of natural capital based conservation:

Stop financial markets taking over nature. Our world is \#notforsale message to \#natcap13 https://pbs.twimg.com/media/BZIQ3RJIcAAMjRr.jpg (@wdmuk 8:39 AM, 21 Nov 2013). ${ }^{42}$

As WFNC organizers began to lose control of the narrative in the virtual sphere, their frustration became readily apparent. Programme Director Jonathan Hughes (@ JonnyEcology), for example, responded angrily when respected institutions began to question the Forum's motives. In one instance, where the Just World Institute (@EthicsEdinburgh) tweeted that "none [of the reasons given for attending the WFNC] mentions protecting the natural world", Hughes shot back: "tell me, does the JWI officially have a blanket policy on silencing debate on all aspects of \#naturalcapital" ${ }^{43}$ His comment suggests that he viewed the WFNC as a public sphere of deliberation and that any challenge to its legitimacy was paramount to "silencing debate". Unwilling to accept this assessment, I pointed out that "[d]issent is part of real debate", and I contrasted the twitter-based dissent to what was "happening in [his] CEOs club". ${ }^{44}$ Hughes dismissed this point saying it was "\#misinformation". ${ }^{45}$

Despite the refrain that the aim of the WFNC was "to provide a platform for debate" and that "[a]11 views [were] welcome on this complex subject", ${ }^{46}$ the sense among skeptics was that only dissent within certain bounds was acceptable. Arguments in favor of protecting the intrinsic value of nature, for example, were permissible since they were viewed as complementary to capitalist forms of conservation. But any perspective that wholly rejected the capitalist framing or challenged the financialization of nature was treated as extreme, meddlesome, and unwelcome. Frustration that the discourse on twitter did not reflect this sanctioned narrative extended to WFNC supporters and delegates as well. A user called @3blnow, for example, called opponents of the WFNC “completely nuts!", telling them to "[g]et a clue" and "stop being a nuisance". ${ }^{47}$ Seb Dunnett 
(@sebdunnett), a delegate, also complained of "the horde of tweeters clogging up [his] \#natcap13 feed!" ${ }^{48}$ apparently perceiving the intervention as an invasion of digital territory. In the immediate lead-up to and during the event, dissent overwhelmed the official narrative carried on \#natcap13 so that anybody tuning in via social media received a very different message about natural capital to the one the WFNC had intended. One user (@ bobgreid), commented, for example, that the WFNC was "more controversial than [he had] imagined". 49

The controversy was also more than the WFNC organizers themselves had anticipated. Event Manager Bruce Wilson explained that "with any other event that we [the Scottish Wildlife Trust] do ... you can guarantee that the only people using the hashtag are the people in the conference ... but with [the WFNC], you were also getting externals drawn in, and at first I was very worried" (Wilson, interview, 14 Oct 2014).$^{50}$ There were several ways they misjudged how the event would be received. In their attempt "to pitch the conference at a level where CEOs would attend" (Wilson, interview, 14 Oct 2014), for example, they alienated many who typically provide the base of their support. Selecting RBS as the headline sponsor may have legitimated the event in the eyes of the business community, but it simultaneously discredited it in the eyes of many others by fostering questionable alliances. Wilson, however, did not regret "the fact that [they were] trying to engage senior business leaders", asserting that "whether we like it or not, that's where the change comes" (Wilson, interview, 14 Oct 2014). In spite of this, the backlash on social media did drive them to make some course corrections along the way.

\section{The Influence of Resistance}

After persistent criticism on social media concerning exclusivity and the lack of real debate, the WFNC organizers responded by making limited (two or three) complementary tickets available to lead members of the oppositional activist organizations (Tamra Gilbert, counter-Forum organizer, interview, 21 Oct 2014). They also began publicizing the "scholarships" they were offering to 
business students. A link to the scholarship announcement, for example, was added immediately below the "CEOs' Club" section on the "Who Should Attend?" page of the WFNC website. But these gestures were largely geared towards mitigating bad publicity, not facilitating inclusive public deliberation. When I expressed this to Bruce Wilson, explaining that I and many others were still unable to access the event, he responded that they had also made volunteer spaces available; individuals willing to run microphones or work registration were admitted free of charge (Wilson, interview, 14 Oct 2014). The perception that this sort of engagement would have been an acceptable substitute for full participation reveals a lack of understanding about what WFNC opponents were seeking. There are few ways that could position dissenting voices on more unequal footing than by permitting our admittance on the condition we serve as "the help".

More significant concessions were made in the immediate days before the event as Forum organizers struggled to re-gain their hold on public opinion. In an attempt to stem the rising opposition, Jonathan Hughes joined the World Development Movement's Nick Dearden on BBC Radio Scotland to discuss the growing controversy. This accommodation is not likely to have been made without the strong counterpublic narrative emanating from social media. As Wilson explained, they were anxious in the moment that their message was "getting diluted" and "people [weren't] going to have a clue what [the WFNC was] all about" (Wilson, interview, 14 Oct 2014). Though he noted in hindsight that the controversy may have helped them to gain greater media coverage (Wilson, interview, 14 Oct 2014), this coverage was qualitatively different to that which would have existed without the counterpublic narrative. The publicity that emerged framed the WFNC (and the concept of natural capital itself) as contested, rather than commonsense and logical. These are substantial impacts that activist resistance, including that on social media, had on the course of events.

The most significant influence of the counterpublic, however, came after the Forum when WFNC 
organizers cooperated with the World Development Movement to coordinate a "roundtable" discussion at Scottish Parliament. This roundtable was strikingly different to the WFNC, primarily in that it was at no expense to participants, and diverse perspectives were (literally) given an equal seat at the table. While there were several factors that led to the roundtable (e.g. a letter writing campaign, image repair, and legislative interest), the opportunity would not have existed without the very public outcry during the WFNC. Indeed, when asked if it would have happened without the dissent on twitter, Wilson, who co-organized the event, said "it probably wouldn't have needed to" (Wilson, interview 14 Oct 2014). In his view, the roundtable was necessary to clear up misunderstanding about what the Scottish Wildlife Trust was trying to achieve in organizing the WFNC. Wilson saw it as an opportunity to clarify his organization's position and "come to consensus on what we do agree on" which, he claimed, "is about $90 \%$ of [the issues]" (Wilson, interview 14 Oct 2014).

Brett's assessment from attending that event was not at all that there is majority consensus or that there was misunderstanding of WFNC activities. While there may be shared interests (i.e. both sides are broadly in favor of conservation), there are fundamental differences in what that conservation looks like, how it is achieved, and even the very language that is used to talk about it. Our point here, however, is that the roundtable came into being as a direct consequence of a strong counterpublic challenge to natural capital that largely grew out of a social-media-based and -backed movement. Without this challenge, it is unlikely that the parliamentary meeting would have included skeptical perspectives. Indeed it is plausible to assume that legislative interest would have otherwise manifested in a high-level meeting with only WFNC advocates of natural capital, leading to a very different policy outcome.

Of course, the roundtable should not be viewed as the achievement of a utopian public sphere of deliberation - indeed, many stakeholders (e.g. representatives from local communities where 
conservation happens) were not present, and uneven power relations and unequal access to financial resources for representation in such meetings remain. Furthermore, the effect of this single meeting is rather insignificant relative to what the WFNC achieved in advancing natural capital throughout the embedded political economy. Digital activists may have been able to challenge the official narrative and even force consideration of social and environmental justice concerns within an important legislative meeting, but these achievements are largely marginal.

Natural capital remains dominant and backed by powerful corporate and government actors, such as those that comprise the business-oriented Natural Capital Coalition and Globe, an international organization of national legislators that is working "to fully incorporate the value of natural capital into national accounting frameworks" (Globe 2015). It is important, therefore, to keep perspective and recognize that while social media can be effectively mobilized to challenge dominant narratives and disrupt the status quo, it cannot alone dismantle the embedded power of hegemonic institutions. Indeed, the Scottish Wildlife Trust has made large strides in domestic implementation of natural capital accounting in spite of the challenges described above, and it has been able to build on momentum since the events of 2013, including through a second World Forum in 2015. In fact, opposition to \#natcap15 was significantly less active compared to \#natcap13, a contrast that begs analysis of its own. ${ }^{51}$

\section{Section V: Conclusion}

Without question, the first WFNC was an important moment in the production of "valued" nature that is, of course, a very narrow and particular kind of monetarily valued nature - and the counterpublic that emerged from dissent on social media undoubtedly played an influential role in that process, namely by exposing the notion of economic valuation itself as problematic and controversial. Though WFNC organizers maintained throughout the \#natcap13 conflict that the purpose of their event was to foster debate between diverse perspectives, this claim was not 
supported by action. In fact, in a candid moment nearly a year later, Bruce Wilson acknowledged what the opposition had asserted all along: the WFNC was about implementation, not deliberation. In his words, “it wasn't so much a debating conference, it was more a 'here's how you can do this' if you're a big company that's thinking about being engaged with [natural capital] issues" (Wilson, interview, 14 Oct 2014). Reflecting on the way that the public perceived this contradiction and the way it galvanized opposition, Wilson added "we're much more aware now that there are people with reservations ... I think we'll try to make some sort of allowance for that and build that in some way into [future] events" (Wilson, interview, 14 Oct 2014). While this paints a rather optimistic picture about the power new digital technology has in disrupting exclusionary deliberation and challenging hegemonic narratives, it is important to grasp the broader conceptual insights that this case has to offer - that is, to understand what \#natcap13 can tell us about public spheres of deliberation, counterpublic organization, and agonistic confrontation in a new digitally-mediated world.

From one perspective, the differences between new digital technologies and earlier means of communication do not have substantial effect on counterpublic organization. As we explained above, Papacharissi suspects that "internet-based technologies will adapt themselves to the current political culture, rather than create a new one" (2002:9). In this case, digital counterpublics may simply reflect existing politics and do little to change the balance of power. The virtual sphere may serve to merely "extend [activists'] repertoire of tactics into new territories" without being used to "constitute radically new forms of protest" (Pickerill 2001:370) or transform the existing political landscape. On the other hand, the different rules to communication within virtual space may open debate and deliberation in significant ways. Just as Penney and Dadas (2014) suggest, social media may foster counterpublic activity beyond what would exist otherwise. Indeed it may even, as Dahlberg (2007) suggests, work to radicalize the public sphere.

In the case analyzed here, the virtual sphere empowered Forum opponents to directly engage with 
and very publicly challenge the dominant narrative. Twitter established a different discursive landscape in which counterpublic activity could not as easily be suppressed; it provided an unregulated space of public discourse where no single person could control communication and no party was able to restrict access (assuming that the corporate owners of the platform continue to be neutral). Consequently, dissenting voices could not be excluded from \#natcap13 in the way they were from the WFNC itself.

As Warner (2002) explains, publics are not created from single texts. They are, rather, created by "the concatenation of texts through time" (Warner 2002:90). In traditional print and web 1.0 media, discourse is mediated by agents that control the means of communication and, therefore, the public they construct is the product of structural power. Web 2.0 media, by contrast, enable countless contributors to create the texts that define its public. This is evidenced by their extensive use across the political spectrum, in underdeveloped communities, and in remote areas around the world (Sullivan 2008:15).

The Twitter platform is transnational and non-exclusionary, at least by design, in the sense that tweeting on a hashtag by particular users cannot easily be prevented. In practice, of course, not everybody has equal resources or time to dedicate to social media engagement. Nevertheless, the concatenation of texts in the 'anti-structural' (Sullivan 2008:15) spaces of the virtual sphere eliminates barriers to engagement and helps to level the playing field between dominant and subaltern voices within the public sphere. More significantly though, it reduces the need for a counter-hegemonic sphere in which to challenge deliberations that exclude certain groups or classes (notwithstanding the important functions of counterpublics as "spaces of withdrawal and regroupment" or "training grounds for agitational activities directed toward wider publics"; Fraser 1990:68). Thus, instead of merely challenging the dominant discourse of higher powered actors, it becomes possible to displace it. Rather than producing and promoting a separate competing 
counter-narrative, it becomes possible to mobilize popular opinion by simply hijacking one that already exists. The efficacy of this tactic is clear in the way \#natcap13 ended up communicating the contested nature of natural capital, instead of what the WFNC had intended.

The promise of such "liberation technology", however, is tempered by the nature of what Fraser (1990) refers to as "weak publics" - that is, publics "whose deliberative practice consists exclusively in opinion-formation and does not also encompass decision-making" (1990:75). Twitter-based counterpublics are weak publics, as compared for example to the dominant public of the WFNC where business, government, and the elite of civil society set an international agenda for capitalist nature conservation. Despite the success of the \#natcap13 counterpublic in securing a position at the parliamentary roundtable, it is important to not overstate the power of a medium like Twitter. Its open nature and unregulated character do, indeed, enable contestation in empowering ways. But its discourse, nevertheless, remains marginal. Activities on social media can influence policy, ${ }^{52}$ but unless they can also dismantle existing structural power, they provide only temporary and fleeting moments of progress. New digital technologies are potent tools in the struggle between differently powered actors in the political economy, but they should be viewed as complementary to (and used in conjunction with) various other means of resistance aimed at dismantling entrenched structural power and enacting radical political change.

\section{References}

Adams PC (1996) Protest and the Scale Politics of Telecommunications. Political Geography 15(5): 419-441.

Arsel M and Büscher B (2012) Nature ${ }^{\mathrm{TM}}$ Inc.: Changes and Continuities in Neoliberal Conservation and Market-based Environmental Policy. Development and Change 43:53-78

Bartlett, J (2014) The Dark Net. London: Random House.

Bayard de Volo L and Hall L K (2015) I Wish All the Ladies Were Holes in the Road": The US Air Force Academy and the Gendered Continuum of Violence. Signs: Journal of Women in Culture and Society 40(4):865-889

Bozionelos N (2014) Careers patterns in Greek academia: social capital and intelligent careers, but for whom? Career Development International 19(3):264-294

Brockington D and Duffy R (2010) Capitalism and Conservation: The Production and Reproduction of Biodiversity Conservation. Antipode 42(3):469-484 
Bulmer M (1982) When Is Disguise Justified? Alternatives to Covert Participant Observation. Qualitative Sociology 5:251-264

Büscher B, Sullivan S, Neves K, Igoe J and Brockington D (2012) Towards a Synthesized Critique of Neoliberal Biodiversity Conservation. Capitalism Nature Socialism 23:4-30

Cammaerts B (2008) Critiques on the participatory potentials of Web 2.0. Communication, culture \& critique $1(4): 358-377$

Carver L and Sullivan S (2014) "Measuring the value of what and for whom? Observations from the first World Forum for Natural Capital."

http://thestudyofvalue.org/2014/02/03/observations-first-world-forum-natural-capital-2/ [last accessed 28 Dec 2016]

Castree N (2008a) Neoliberalising nature: processes, effects, and evaluations. Environment and Planning A 40:153-173

Castree N (2008b) Neoliberalising nature: the logics of deregulation and reregulation. Environment and Planning A 40:131-152

Checker M (2017) Stop FEMA Now: Social Media, Activism and the Sacrificed Citizen. Geoforum (in press).

Coleman G (2014) Hacker, Hoaxer, Whistleblower, Spy: The Many Faces of Anonymous. London: Verso.

Collinson, I (2009) Everyday Readers : Reading and Popular Culture. London, GB: Equinox Publishing Ltd.

Corson C, Brady B, Zuber A, Lord J and Kim A (2015) The right to resist: disciplining civil society at Rio+20. The Journal of Peasant Studies 42(3-4):1-20

Dahlberg L (2007) The Internet, deliberative democracy, and power: Radicalizing the public sphere. International Journal of Media \& Cultural Politics 3:47-64

Davis A (2010) New media and fat democracy: the paradox of online participation1. New Media \& Society 12:745-761

de Socio M (2010) Geographers Mobilize: A Network-Diffusion Analysis of the Campaign to Free Ghazi-Walid Falah. Antipode 42(2): 310-335.

Declaration (2012) "20 Financial Institutions Make Far-Reaching Commitment on Natural Capital." http://www.naturalcapitaldeclaration.org/2012/05/20-financial-institutions-sign-ncd/ [last accessed 2 Feb 2015]

Diamond L (2010) Liberation Technology. Journal of Democracy 21:69-83

Edwards R (2013) "Wildlife conference under attack for 'selling off nature to multinationals'." The Guardian. http://www.theguardian.com/environment/2013/nov/13/wildlife-conferenceselling-nature [last accessed 27 Feb 2015]

Ellis C, Adams T and Bochner A (2011) Autoethnography: An Overview. Qualitative Social Research 12(1):10

Ellis C and Bochner A (2000) Autoethnography, Personal Narrative, Reflexivity. In: N Denzin and Y Lincoln (eds) Handbook of Qualitative Research. Thousand Oaks: Sage

Fisher C B \& Anushko A E (2008) Research Ethics in Social Science. In: P Alasuutari, L Bickman and J Brannen (eds) The SAGE Handbook of Social Research Methods. London: Sage Publications

Fraser N (1990) Rethinking the Public Sphere: A Contribution to the Critique of Actually Existing Democracy. Social Text 25/26:56-80

Globe (2015) "Globe Natural Capital Initiative.” http://globelegislators.org/the-globe-naturalcapital-initiative [last accessed 20 Mar 2015]

Habermas J (1998) Between Facts and Norms: Contributions to a Discourse Theory of Law and Democracy. Cambridge: MIT Press

Habermas J (1991) The Structural Transformation of the Public Sphere: An Inquiry Into a Category of Bourgeois Society. Cambridge: MIT Press

Hawkins R and Silver J (2017) From Selfie to \#Sealfie: Nature 2.0 and the Digital Cultural Politics of an Internationally Contested Resource. Geoforum (in press). 
Hirsch J (2003) The State's New Clothes: NGOs and the Internationalization of States. Rethinking Marxism 15:237-262

Kapoor I (2002) Deliberative Democracy or Agonistic Pluralism? The Relevance of the HabermasMouffe Debate for Third World Politics. Alternatives: Global, Local, Political 27:459-487

Kendall G (2007) What is Critical Discourse Analysis?: Ruth Wodak in Conversation with Gavin

Kendall. Forum on Qualitative Social Research 8(2)

Morozov E (2011) The Net Delusion: How Not to Liberate the World. London: Penguin Books.

Mouffe C (1999) Deliberative Democracy or Agonistic Pluralism? Social Research 66:745-758

Mouffe C (2000) The Democratic Paradox. London: Verso

Papacharissi Z (2002) The virtual sphere: The internet as a public sphere. New Media \& Society, $4: 9-27$

Penney J and Dadas C (2014) (Re)Tweeting in the service of protest: Digital composition and circulation in the Occupy Wall Street movement. New Media \& Society 16:74-90

Pickerill J (2006) Radical Politics on the Net. Parliamentary Affairs 59(2):266-282

Pickerill J (2001) Environmental Internet Activism in Britain. Peace Review 13(3):365-370

Purcell D (2014) The Internet. In Adams PC, Craine J, and Dittmer J (eds.), The Ashgate Research Companion to Media Geography. New York, NY: Routledge.

Roberts J M (2014) New Media and Public Activism: Neoliberalism, the state and radical protest in the public sphere. Bristol: Policy Press

Robertson M (2012) Measurement and alienation: making a world of ecosystem services. Transactions of the Institute of British Geographers 37:386-401

Sullivan S (2008) Conceptualising glocal organisation: from rhizomes to $\mathrm{E}=\mathrm{mc}^{2}$ in becoming posthuman, in Kornprobst, M., Pouliot, V., Shah, N. And Zaiotti, R. (eds.) Metaphors of Globalisation: Mirrors, Magicians and Mutinies, Basingstoke: Palgrave Macmillan.

Sullivan S (2013) Banking Nature? The Spectacular Financialisation of Environmental Conservation. Antipode 45(1):198-217

Sullivan S (2014) The natural capital myth; or will accounting save the world? Preliminary thoughts on nature, finance and values. LCSV Working Paper Series No. 3

Warf B and Grimes J (1997) Counterhegemonic discourses and the Internet. Geographical Review 87(2): 259-274

Warner M (2002) Publics and Counterpublics. New York: Zone Books

Weber M (1947) The Theory of Social and Economic Organisation. New York: Oxford University Press

Wodak R and Meyer M (2009) Critical Discourse Analysis: History, Agenda, Theory and Methodology. In R Wodak and M Meyer (eds) Methods of Critical Discourse Analysis (pp 1-33). 2nd ed. London: Sage Publications

World Forum (2015) "Who Should Attend?" http://www.naturalcapitalforum.com/who-shouldattend [last accessed 8 Feb 2016]

World Forum (2013a) “About." http://www.naturalcapitalforum.com/about [last accessed 6 May 2014]

World Forum (2013b) “Who Should Attend?” http://www.naturalcapitalforum.com/who-shouldattend [last accessed 22 Jun 2014]

World Forum (2013c) “CEOs' Club.” http://www.naturalcapitalforum.com/ceosclub [last accessed 22 Jun 2014]

\footnotetext{
${ }^{1}$ Discounts were available during early registration, and "non-corporate" registrants could gain admission for $£ 595$.

${ }^{2}$ Entrance to the CEOs' Club was later modified to be by invitation and application.

${ }^{3}$ Nestle chairman Peter Brabeck-Letmathe can be seen in the documentary We Feed the World making his case for the privatization of water.

${ }^{4}$ Not all digital activism, however, is individualist or rooted in branding and marketing the "Self". The anarchic "hacktivist" collective Anonymous, for example, embodies neither. As encapsulated in the group's signature tagline "We are Anonymous" - using the collective "we" and trading personal vanity for anonymity - it is clear that (at least some) digital activism embodies the antithesis of neoliberal individualism.
} 
${ }^{5}$ https://twitter.com/NatCapForum/status/334605003736113152

${ }^{6} \mathrm{https} / / /$ twitter.com/NatCapForum/status/335080286373167106

${ }^{7}$ https://twitter.com/NatCapForum/status/336411244892389377

${ }^{8} \mathrm{https} / / /$ twitter.com/NatCapForum/status/336792483419803649

${ }^{9}$ https://twitter.com/ginbat/status/334608147350167552

${ }^{10} \mathrm{https}: / /$ twitter.com/NatCapForum/status/334659456392630274; https://twitter.com/AllanBoat/status/334671724362743808

${ }^{11} \mathrm{https}: / /$ twitter.com/ginbat/status/334670388476919808

${ }^{12} \mathrm{https}: / /$ twitter.com/ginbat/status/334672157021962240

${ }^{13}$ Section IV is written in the voice of the first author whose autoethnographic account is presented here.

${ }^{14} \mathrm{https} / / /$ twitter.com/bmatulis/status/352100669576056834; note that $£ 595$ was the discounted "early-bird", noncorporate rate.

${ }^{15} \mathrm{https}: / /$ twitter.com/bmatulis/status/352487434795237376; https://twitter.com/JonnyEcology/status/352706183058042880

${ }^{16} \mathrm{https}: / /$ twitter.com/bmatulis/status/352444349063249921

${ }^{17} \mathrm{https} / / /$ twitter.com/bmatulis/status/353425197753303040

${ }^{18} \mathrm{https} / / /$ twitter.com/bmatulis/status/363947892467175424

${ }^{19} \mathrm{https} / / /$ twitter.com/bmatulis/status/364385787074183169

${ }^{20} \mathrm{https} / / /$ twitter.com/bmatulis/status/393529125564334081

${ }^{21} \mathrm{https} / / /$ twitter.com/bmatulis/status/397406249597145088

${ }^{22}$ https://twitter.com/NatCapForum/status/393393786786557952

${ }^{23} \mathrm{https} / / /$ twitter.com/reddmonitor/status/393440948379607041

${ }^{24} \mathrm{https} / / /$ twitter.com/NatCapForum/status/393673226515013632

${ }^{25} \mathrm{https} / / /$ twitter.com/reddmonitor/status/394779630764167168

${ }^{26} \mathrm{https} / / /$ twitter.com/EcoLabs/status/401406895304351744

${ }^{27}$ The WFNC programme was released on 10 September 2013; https://twitter.com/NatCapForum/status/377436015813619712

${ }^{28} \mathrm{http} / / /$ ottawa.ctvnews.ca/the-oscar-selfie-seen-around-the-world-1.1712204

${ }^{29} \mathrm{https} / / /$ twitter.com/Econopoly_/status/401387769311670273

${ }^{30} \mathrm{https} / / /$ twitter.com/EcoLabs/status/401391214869479425

${ }^{31} \mathrm{https}: / /$ witter.com/EthicsEdinburgh/status/401517468570902529

${ }^{32} \mathrm{https} / / /$ twitter.com/lastbid/status/402142209186615297

${ }^{33} \mathrm{https}: / /$ twitter.com/nickdearden75/status/402455960829952000

${ }^{34} \mathrm{https}: / /$ twitter.com/bmatulis/status/402841393296457729

${ }^{35} \mathrm{https} / / /$ twitter.com/ricjl/status/403142127732789250

${ }^{36}$ https://twitter.com/Paco_Cervera/status/403204539915845633

${ }^{37} \mathrm{https} / / /$ twitter.com/ohbaines/status/403430532823793664

${ }^{38} \mathrm{https}: / /$ twitter.com/SaveOurWoods/status/403532294084124672

${ }^{39} \mathrm{https} / / /$ twitter.com/BillLinton1/status/403565946024914945

${ }^{40} \mathrm{https}: / /$ witter.com/TonyDickinson2/status/403568284617801728

${ }^{41}$ Twitter's algorithm for determining "top tweets" is a proprietary secret, but is supposedly comprised of some combination of views, retweets, favorites, interactions, and reach beyond what is expected from a particular user's "normal" activity (i.e. it isn't just the most popular tweet from the user with the most followers).

${ }^{42}$ https://twitter.com/GlobalJusticeUK/status/403442552210481152; N.B. the World Development has since become Global Justice Now, changing its twitter handle from @wdmuk to @ GlobalJusticeUK.

${ }^{43} \mathrm{https} / / /$ twitter.com/EthicsEdinburgh/status/401896285835657216; https://twitter.com/JonnyEcology/status/402143348032421888

${ }^{44} \mathrm{https}: / /$ twitter.com/bmatulis/status/402162792457068544

${ }^{45}$ https://twitter.com/JonnyEcology/status/402164487177789440

${ }^{46} \mathrm{https}: / /$ twitter.com/JonnyEcology/status/401399202141319169

${ }^{47}$ https://twitter.com/3blnow/status/403575831462948864; https://twitter.com/3blnow/status/403840865686519808; https://twitter.com/3blnow/status/403870454303440896

${ }^{48} \mathrm{https}: / /$ twitter.com/sebdunnett/status/403911354274566144

${ }^{49} \mathrm{https} / / /$ twitter.com/bobgreid/status/402835094354034688

${ }^{50}$ All interviews were conducted by the first author with complete knowledge of the oppositional role he had played in the counter-Forum.

${ }^{51}$ One possible explanation (as expressed to me by users who were active on \#natcap13) is that anti-capitalist activists were preoccupied with planning actions for the United Nations Conference on Climate Change (\#COP21), which took place the week following \#natcap15.

${ }^{52}$ In addition to \#natcap13, consider the influence of broad digital movements for net neutrality and the challenges they have posed to regressive policies like SOPA and PIPA. 